\title{
Sonochemical Syntheses of a One-Dimensional Mg(II) Metal-Organic Framework: A New Precursor for Preparation of MgO One-Dimensional Nanostructure
}

\author{
Arineh Tahmasian, ${ }^{1}$ Ali Morsali, ${ }^{1}$ and Sang Woo Joo $^{2}$ \\ ${ }^{1}$ Department of Chemistry, Faculty of Sciences, Tarbiat Modares University, P.O. Box 14117-13116, Tehran, Iran \\ ${ }^{2}$ School of Mechanical Engineering, Yeungnam University, Gyeongsan 712-749, Republic of Korea \\ Correspondence should be addressed to Sang Woo Joo; swjoo@yu.ac.kr
}

Received 21 April 2013; Accepted 12 August 2013

Academic Editor: Yanqiu Zhu

Copyright (C) 2013 Arineh Tahmasian et al. This is an open access article distributed under the Creative Commons Attribution License, which permits unrestricted use, distribution, and reproduction in any medium, provided the original work is properly cited.

\begin{abstract}
Nanostructure of a $\mathrm{Mg}^{\mathrm{II}}$ metal-organic framework (MOF), $\left\{\left[\mathrm{Mg}(\mathrm{HIDC})\left(\mathrm{H}_{2} \mathrm{O}\right)_{2}\right] \cdot 1.5 \mathrm{H}_{2} \mathrm{O}\right\}_{n}(\mathbf{1})\left(\mathrm{H}_{3} \mathrm{IDC}=4,5\right.$-imidazoledicarboxylic acid), was synthesized by a sonochemical method and characterized by scanning electron microscopy, X-ray powder diffraction, IR spectroscopy, and elemental analyses. The effect of concentration of starting reagents on size and morphology of nanostructured compound 1 has been studied. Calcination of the bulk powder and nanosized compound 1 at $650^{\circ} \mathrm{C}$ under air atmosphere yields $\mathrm{MgO}$ nanostructures. Results show that the size and morphology of the $\mathrm{MgO}$ nanoparticles are dependent upon the particles size of compound 1 .
\end{abstract}

\section{Introduction}

Metal-organic frameworks (MOFs) constructed by metal ions and multifunctional organic linkers have attracted a great deal of interest in recent years [1-7]. Their high internal surface area, light weight, high porosity, and low volumetric density give them great opportunity for the potential applications in ion exchange [8], chemical sensor [9-13], catalysis [14-17], gas storage [18-21], and separation [22]. Recently, 4,5-imidazoledicarboxylic acid $\left(\mathrm{H}_{3} \mathrm{IDC}\right)$ was used to synthesize various functional metal-organic hybrid frameworks [23-29]. This ligand has three pH-dependent abstractable protons and six donor sites, which can be exploited for the synthesis of a variety of hybrid solids through a number of flexible coordination modes [30]. However, most of the MOFs are constructed from transitional metals but rare earth metals and alkali or alkaline-earth metals based MOFs are scarcely investigated [31-34]. Compared to the transitional metals, alkali metal units are lighter, which can offer a lower framework density and lead to an increase in gravimetric gas sorption capacity [35-37]. Among the s-block metals, the large polarizing power of $\mathrm{Mg}^{\mathrm{II}}$ can provide a strong coordination bond with oxygen. There are few porous hybrid frameworks based on $\mathrm{Mg}^{\text {II }}$ that have been reported [38-43].

Generally, porous materials are synthesized by slow diffusion, hydrothermal, and solvothermal synthesis methods [44-46]. In many cases a long reaction times, high reaction temperatures and pressures are required. To date a more efficient synthetic approach to MOFs still remains a challenge. Recently, a microwave assisted hydrothermal method is applied to prepare MOFs. This method is a highly efficient route to MOFs, although some reactions finish within several hours, but high reaction temperature and pressure are still needed $[47,48]$. In the past two decades, sonochemical methods have been widely used in organic synthesis [49]. Compared with traditional techniques, sonochemical method is more convenient and easily controlled. A large number of organic reactions have been carried out under ultrasound irradiation in high yields within a short reaction time. To date application of ultrasonic method for the construction of MOFs remains largely unexplored [50].

In the present work, a $\mathrm{Mg}^{\mathrm{II}}$ metal-organic framework with ligand $\mathrm{H}_{3} \mathrm{IDC},\left\{\left[\mathrm{Mg}(\mathrm{HIDC})\left(\mathrm{H}_{2} \mathrm{O}\right)_{2}\right] \cdot 1 \cdot 5 \mathrm{H}_{2} \mathrm{O}\right\}_{n} \quad$ (1) $\left(\mathrm{H}_{3} \mathrm{IDC}=4,5\right.$-imidazoledicarboxylic acid $)$ was synthesized 


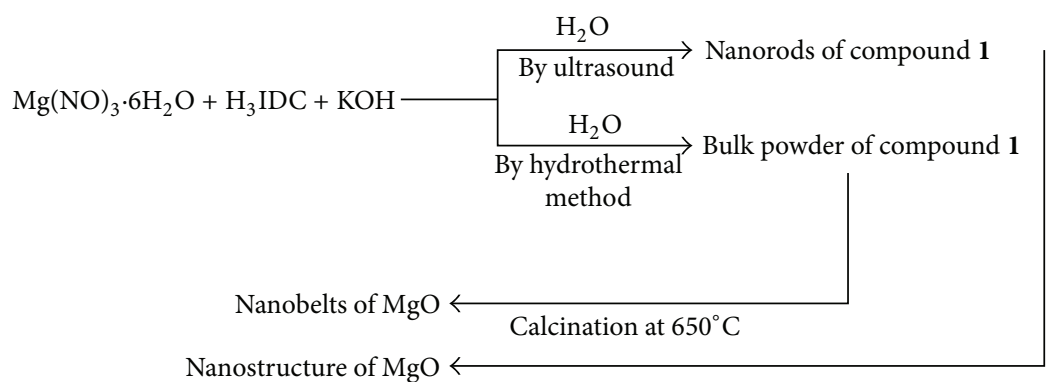

Scheme 1: Materials produced and synthetic methods.

under ultrasonic irradiation. Conversion of the compound $\mathbf{1}$ into nanostructured magnesium oxide $(\mathrm{MgO})$ by calcination at $650^{\circ} \mathrm{C}$ was also investigated. Synthesis of magnesium oxide nanostructures has been given much attention due to its applications in catalysis, toxic waste remediation, and as an additive in refractory, paint, and superconductor products [51-53].

\section{Experimental}

2.1. Materials and Physical Techniques. All reagents for the synthesis and analysis were commercially available from Merck Company and used as received. Doubly distilled water was used to prepare aqueous solutions. Ultrasonic generators were carried out on a SONICA-2200 EP, input: 50-60 Hz/305 W. Melting points were measured on an Electrothermal 9100 apparatus. Microanalyses were carried out using a Heraeus CHN-O-Rapid analyzer. The infrared spectra were recorded on a Nicolet Fourier Transform IR, Nicolet 100 spectrometer in the range $500-4000 \mathrm{~cm}^{-1}$, using the $\mathrm{KBr}$ disk technique. The simulated XRD powder patterns based on single crystal data were prepared using Mercury software [54]. X-ray powder diffraction (XRD) measurements were performed using a Philips X'pert diffractometer with monochromated Co $k \alpha$ radiation $(k=1.78897 \AA)$. The samples were characterized by a scanning electron microscope (SEM) (Philips XL 30 and S-4160) with gold coating.

2.2. Synthesis of $\left\{\left[\mathrm{Mg}(\mathrm{HIDC})\left(\mathrm{H}_{2} \mathrm{O}\right)_{2}\right] \cdot 1.5 \mathrm{H}_{2} \mathrm{O}\right\}_{n}$ (1). The compound 1 was prepared according to the reported method [55]. A mixture of $\mathrm{Mg}\left(\mathrm{NO}_{3}\right)_{2} \cdot 6 \mathrm{H}_{2} \mathrm{O}(0.5 \mathrm{mmol}, 0.128 \mathrm{~g}), \mathrm{H}_{3} \mathrm{IDC}$ $(0.5 \mathrm{mmol}, 0.078 \mathrm{~g})$, and $\mathrm{KOH}(1 \mathrm{mmol}, 0.056 \mathrm{~g})$ in a molar ratio of $1: 1: 2$ was dissolved in distilled water $(8 \mathrm{~mL})$ and stirred for $1 \mathrm{~h}$ in air. The solution was transferred into $23 \mathrm{~mL}$ Teflon-lined Parr autoclave and heated at $160^{\circ} \mathrm{C}$ for $24 \mathrm{~h}$. The mixture was allowed to cool to room temperature and the resulting colorless crystals were filtered off, washed with distilled water and ethanol, and air-dried [46] ((0.084 g yield: $69.4 \%$ ), m.p. $>300^{\circ} \mathrm{C}$. (Anal. calcd for $\mathrm{C}_{5} \mathrm{H}_{9} \mathrm{MgN}_{2} \mathrm{O}_{7.5}: \mathrm{C}$, 24.87; H, 3.76; N, 11.60. Found: C, 24.89; H, 3.28; N, 11.65\%.) IR $\left(\mathrm{cm}^{-1}\right)$ selected bands: $3414(\mathrm{w}), 1579(\mathrm{~s}), 1471(\mathrm{~s}), 1396(\mathrm{~s})$, 1247 (m), $1105(\mathrm{~m}), 837(\mathrm{~m}), 674(\mathrm{~m}))$.

2.3. Synthesis of $\left\{\left[\mathrm{Mg}(\mathrm{HIDC})\left(\mathrm{H}_{2} \mathrm{O}\right)_{2}\right] \cdot 1.5 \mathrm{H}_{2} \mathrm{O}\right\}_{n}$ (1) Nanostructure by Using Sonochemical Method. To prepare nanosized

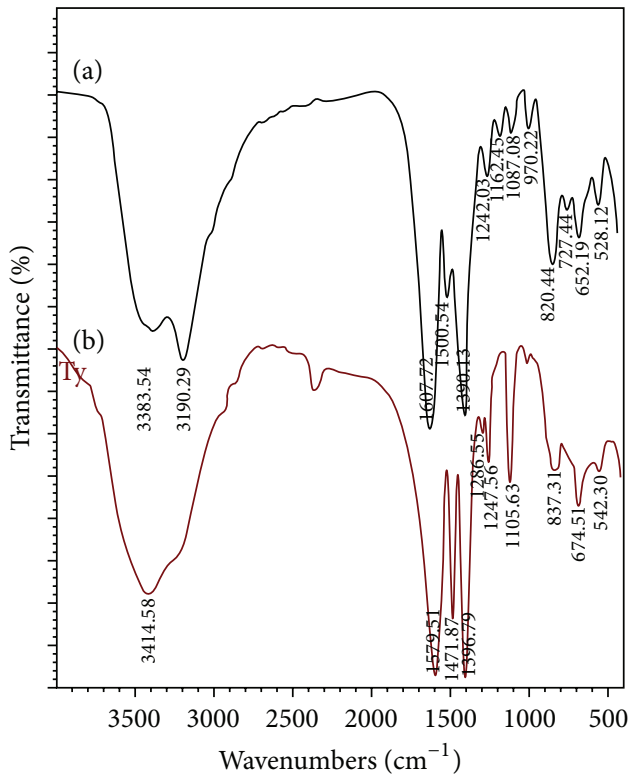

FIGURE 1: IR spectra of (a) nanostructured compound 1 produced by sonochemical method in concentration of initial regents $\left[\mathrm{HL}^{2-}\right]$ $=\left[\mathrm{Mg}^{2+}\right]=0.05$ and (b) bulk powder of compound $\mathbf{1}$.

$\left\{\left[\mathrm{Mg}(\mathrm{HIDC})\left(\mathrm{H}_{2} \mathrm{O}\right)_{2}\right] \cdot 1.5 \mathrm{H}_{2} \mathrm{O}\right\}_{n}(\mathbf{1}), 20 \mathrm{~mL}$ of an aqueous solution of the ligand $\mathrm{H}_{3}$ IDC $(0.05 \mathrm{M})$ and potassium hydroxide $(0.1 \mathrm{M})$ was positioned in a high-density ultrasonic probe, operating at $50 \mathrm{~Hz}$ with a maximum power output of $305 \mathrm{~W}$. Into this solution $20 \mathrm{~mL}$ of an aqueous solution of magnesium nitrate $(0.05 \mathrm{M})$ was added dropwise. The obtained precipitates were filtered off, washed with water andethanol, and air-dried (m.p. $>300^{\circ} \mathrm{C}$. (Found: C, 24.84; H, 3.22; N, 11.67\%.). IR ( $\left.\mathrm{cm}^{-1}\right)$ selected bands: $3383(\mathrm{w}), 3190(\mathrm{w})$, 1607 (br), 1500 (m), 1390 (s), 1242 (m), 820 (m), 652 (m)).

For studying the effect of concentration of initial reagents on size and morphology of nanostructured compound $\mathbf{1}$, the above processes were done under the following concentration condition of initial reagents: $\left[\mathrm{HL}^{2-}\right]=\left[\mathrm{Mg}^{2+}\right]=0.025 \mathrm{M}$.

\section{Preparation of MgO Nanostructures}

For preparation of $\mathrm{MgO}$ nanostructure and also for investigating the size effect of precursor $\mathbf{1}$ on the size and morphology of the $\mathrm{MgO}$ nanostructures, calcination of bulk 


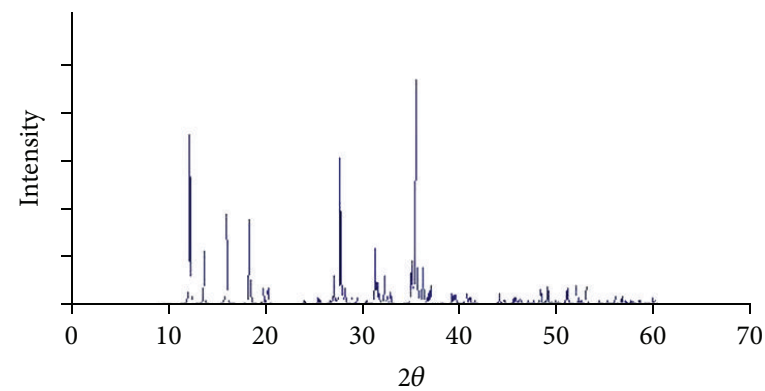

(a)

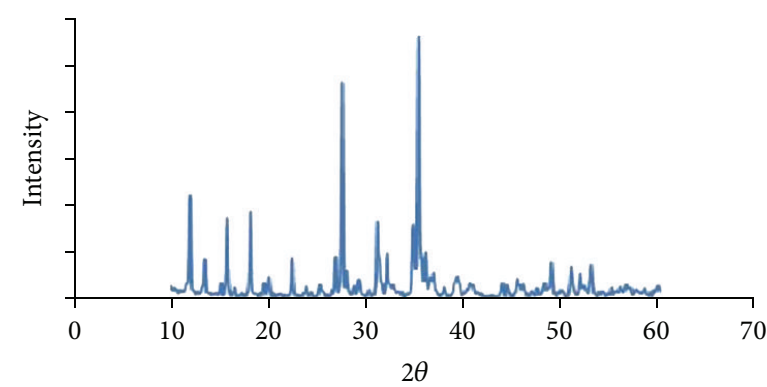

(b)

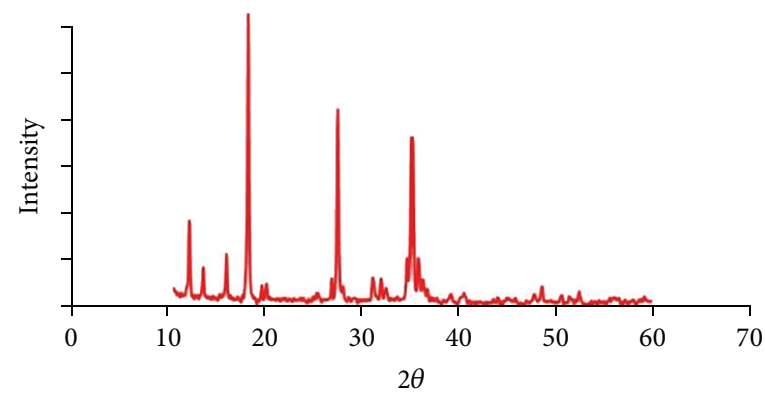

(c)

FIGURE 2: XRD patterns; (a) simulated pattern based on single crystal data of compound 1, (b) bulk powder of $\mathbf{1}$, and (c) nanostructured compound 1 prepared by sonochemical process in concentration of initial reagents $\left[\mathrm{Mg}^{2+}\right]=\left[\mathrm{L}^{3-}\right]=0.05 \mathrm{M}$.

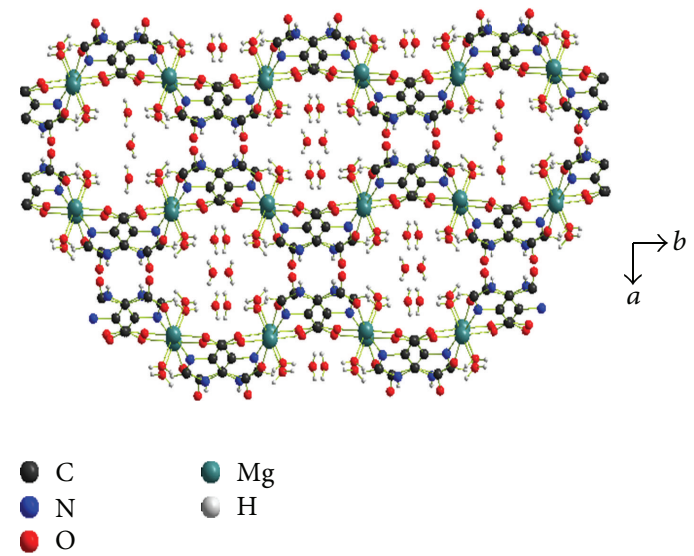

FIGURE 3: A fragment of the 3D framework in compound $\mathbf{1}$, viewed along $c$ direction.

powder and nanosized compound 1 was done at $650^{\circ} \mathrm{C}$ in static atmosphere of air for $4 \mathrm{~h}$. IR spectrum and powder XRD diffraction show that calcination was completed and the entire organic compound was decomposed.

\section{Results and Discussion}

The reaction between 4,5-imidazoledicarboxylic acid $\left(\mathrm{H}_{3} \mathrm{IDC}\right)$ and potassium hydroxide with magnesium nitrate led to formation of a metal-organic framework $\{[\mathrm{Mg}(\mathrm{HIDC})$ $\left.\left.\left(\mathrm{H}_{2} \mathrm{O}\right)_{2}\right] \cdot 1.5 \mathrm{H}_{2} \mathrm{O}\right\}_{n}$ (1). Nanostructure of compound 1 was obtained in aqueous solution under ultrasonic irradiation, while the bulk powder of compound $\mathbf{1}$ was obtained under hydrothermal condition. Scheme 1 gives an overview of the methods used for the synthesis of $\{[\mathrm{Mg}(\mathrm{HIDC})$ $\left.\left.\left(\mathrm{H}_{2} \mathrm{O}\right)_{2}\right] \cdot 1.5 \mathrm{H}_{2} \mathrm{O}\right\}_{n}(\mathbf{1})$ using the two different routes.

The elemental analysis and IR spectra of the nanostructure produced by the sonochemical method and of the bulk material produced by the hydrothermal method are indistinguishable (Figure 1). The symmetric and asymmetric vibrations of the carboxylate group are observed in the regions of $1531-1654$ and $1396-1471 \mathrm{~cm}^{-1}$, respectively. The $\Delta\left(v_{\text {as }}-\right.$ $v_{\text {sym }}$ ) values indicate bidentate chelate coordination mode of HIDC $^{2-}$ in 1 . The strong and broad absorption band in the range of $3400-3500 \mathrm{~cm}^{-1}$ indicates the presence of hydrogenbonded water molecules [55].

Figure 2 shows the comparison of XRD patterns, one simulated from single crystal X-ray data (Figure 2(a)) against the bulk powder of compound $\mathbf{1}$ (Figure 2(b)) and that of a typical sample of compound $\mathbf{1}$ prepared by the sonochemical process, respectively (Figure $2(\mathrm{c})$ ). The comparison between these XRD patterns indicates acceptable matches with slight differences in $2 \theta$. This finding proves the formation of compound $\mathbf{1}$ under hydrothermal and sonochemical processes.

Compound $\mathbf{1}$ is a 3D supramolecular metal-organic framework and crystallizes in the monoclinic space group $\mathrm{C} 2 / \mathrm{c}$ and consists of a $1 \mathrm{D}$ coordination chain of $\mathrm{Mg}^{\mathrm{II}}$ linked by $\mathrm{HIDC}^{2-}$. 1D chains are engaged in hydrogen bonding interactions with coordinate water molecule and carboxylate oxygens forming $2 \mathrm{D}$ supramolecular sheets. These sheets are further linked by hydrogen bonds through uncoordinated imidazole nitrogen and carboxylate oxygen, forming a 3D supramolecular framework with 1D channels occupied by the 


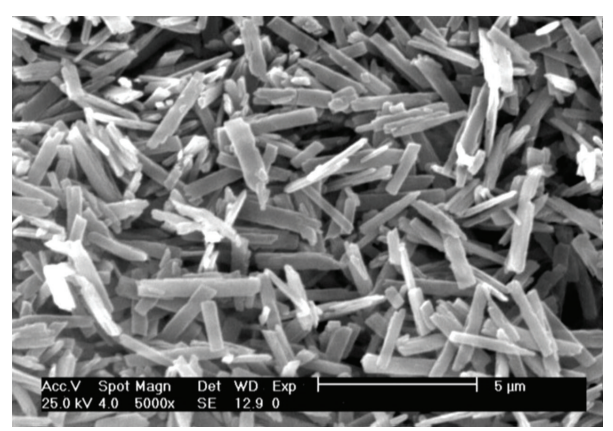

(a)

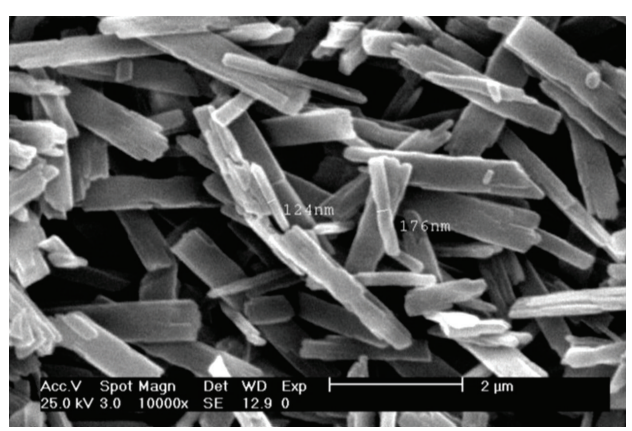

(b)

FIGURE 4: SEM images of compound 1 nanorods prepared by sonochemical process in concentration of initial reagents $\left[\mathrm{Mg}^{2+}\right]=\left[\mathrm{L}^{3-}\right]=$ $0.05 \mathrm{M}$.

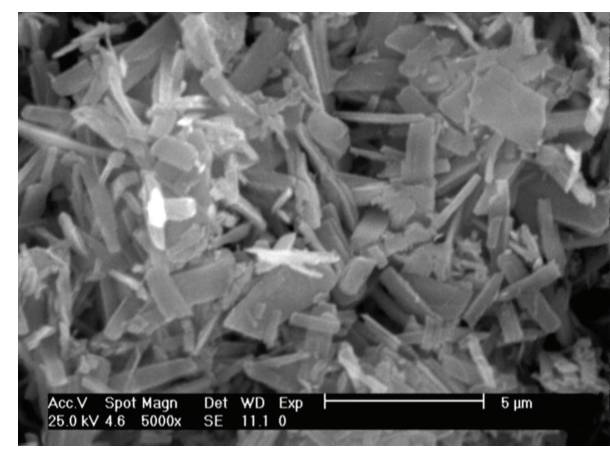

(a)

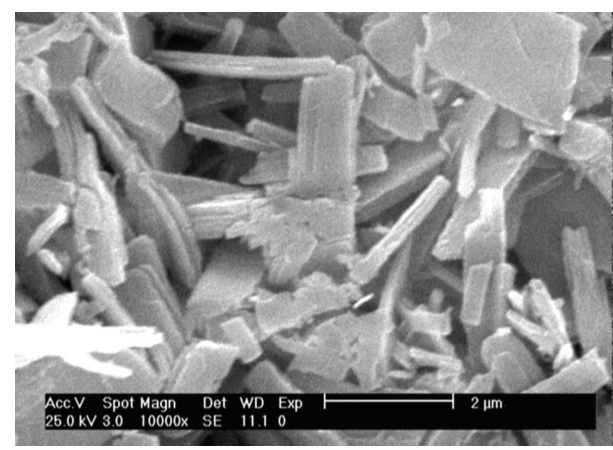

(b)

FIGURE 5: SEM images of compound 1 nanorods prepared by sonochemical process in concentration of initial reagents $\left[\mathrm{Mg}^{2+}\right]=\left[\mathrm{L}^{3-}\right]=$ $0.025 \mathrm{M}$.

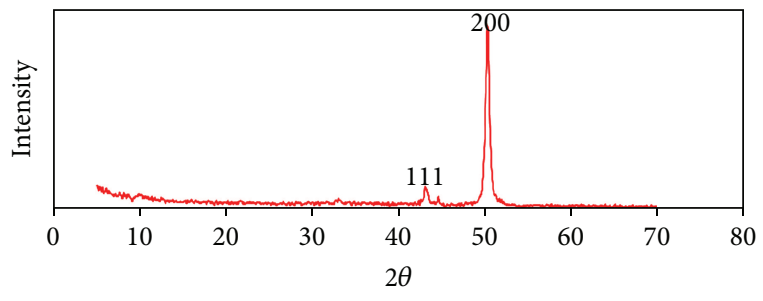

FIGURE 6: XRD pattern of MgO nanostructure prepared by calcination of compound 1 at $650^{\circ} \mathrm{C}$.

water molecules. Figure 3 shows a fragment of framework 1 along the crystallographic $c$ axis showing that $\mathrm{Mg}$ atoms are six coordinate [55].

The reaction between 4,5-imidazoledicarboxylic acid $\left(\mathrm{H}_{3} \mathrm{IDC}\right)$ and potassium hydroxide with magnesium nitrate under ultrasonic irradiation provided a crystalline nanostructure of the general formula $\left\{\left[\mathrm{Mg}(\mathrm{HIDC})\left(\mathrm{H}_{2} \mathrm{O}\right)_{2}\right]\right.$. $\left.1.5 \mathrm{H}_{2} \mathrm{O}\right\}_{n}(\mathbf{1})$. The morphology and size of the compound 1 prepared by the sonochemical method were characterized by scanning electron microscopy (SEM) showing that it is composed of nanorods with sizes about $100 \mathrm{~nm}$. Figure 4 shows the SEM images of the compound 1 obtained under $0.05 \mathrm{M}$ concentration of $\mathrm{HL}^{2-}$ and $\mathrm{Mg}^{2+}$. To investigate the role of the concentration of initial reagents on the nature of products, reactions were performed with different concentrations of magnesium nitrate $(0.025 \mathrm{M})$ and $4,5-$ imidazoledicarboxylic acid $\left(\mathrm{H}_{3} \mathrm{IDC}\right)$ aqueous solutions $(0.025 \mathrm{M})$. The resultant SEM images are illustrated in Figure 5. Nanorods of compound 1 were obtained under both concentrations of initial reagents (Figures 4 and 5). Comparison of IR spectra and XRD patterns shows that the reaction at both concentrations of initial reagents produces the same product. However, size of the nanorods is dependent on the concentration of initial reagents as the nanostructure obtained at higher concentration of initial reagents has more uniform morphology and smaller size.

TGA data of compound 1 indicates a continuous weight loss below $650^{\circ} \mathrm{C}$; this can correspond to thermal removal of the solvent molecules, decomposition of ligand, and the formation of $\mathrm{MgO}$.

There is no extra weight loss above $650^{\circ} \mathrm{C}$, which indicates that the compound $\mathbf{1}$ is completely transformed to $\mathrm{MgO}$ materials following the heat treatment process at $650^{\circ} \mathrm{C}$ [46]. Figure 6 provides the XRD pattern of the residue obtained from calcination of compound 1 . The obtained pattern matches with the standard pattern of cubic $\mathrm{MgO}$ with the lattice parameters $a=4.2112 \AA, Z=4$, and S.G $=$ Fm $3 \mathrm{~m}$ which is the same as the reported values (JCPDS card number 


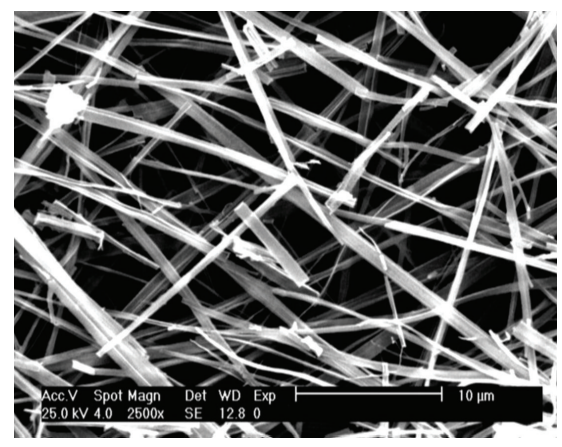

(a)

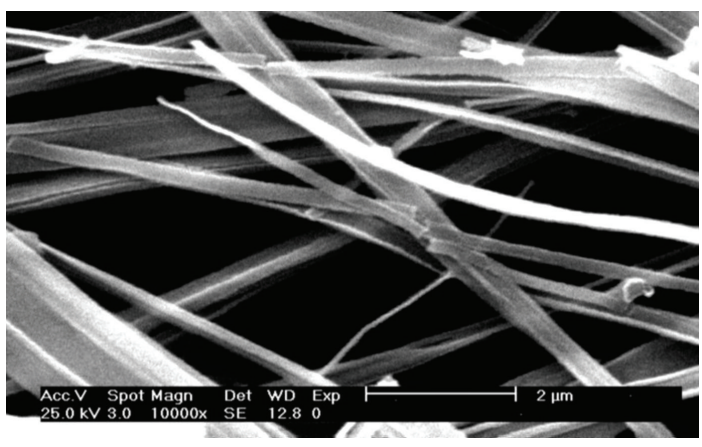

(b)

FIGURE 7: SEM image of MgO nanobelts prepared by calcination of bulk powder of compound 1 at $650^{\circ} \mathrm{C}$.

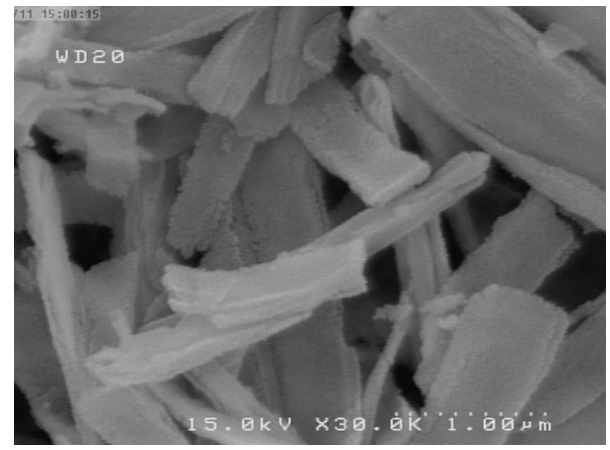

FIGURE 8: SEM image of MgO nanostructure prepared by calcination of compound 1 nanostructure at $650^{\circ} \mathrm{C}$.

45-0946). No characteristic peaks of impurities are detected in the XRD pattern.

Figure 7 shows the SEM images of $\mathrm{MgO}$ nanobelts obtained from calcination of bulk powder of compound $\mathbf{1}$ at $650^{\circ} \mathrm{C}$. As the calcination process was successful for the preparation of $\mathrm{MgO}$ nanobelts, the nanostructured compound 1 prepared by the sonochemical process was also calcinated at $650^{\circ} \mathrm{C}$. Figure 8 shows the SEM image of the resulting $\mathrm{MgO}$ nanostructure. The XRD pattern of the residue shows that the resulting residue was again $\mathrm{MgO}$ with the same lattice parameters which are mentioned above. Comparison between resulting SEM images (Figures 7 and 8 ) indicates that the size of the coordination polymeric precursor correlates to the size and morphology of the formed $\mathrm{MgO}$ nanostructures.

\section{Conclusions}

In conclusion, we have exhibited an efficient, low cost, and environmentally friendly route to produce a $3 \mathrm{D}$ supramolecular metal-organic framework (MOF) based on $\mathrm{Mg}^{\mathrm{II}}$, $\left\{\left[\mathrm{Mg}(\mathrm{HIDC})\left(\mathrm{H}_{2} \mathrm{O}\right)_{2}\right] \cdot 1 \cdot 5 \mathrm{H}_{2} \mathrm{O}\right\}_{n}(\mathbf{1})\left(\mathrm{H}_{3} \mathrm{~L}=4,5\right.$-imidazoledicarboxylic acid) by using ultrasonic method. Nanocrystals of compound 1 were prepared by using ultrasonic method and characterized by scanning electron microscopy, X-ray powder diffraction, IR spectroscopy, and elemental analyses. To prepare the nanostructure of compound $\mathbf{1}$, two different concentrations of initial reagents were tested. Nanorods of compound 1 were obtained under both concentrations. Results show an increase in the nanostructure size as the concentration of initial reagents has decreased. Calcination of compound $\mathbf{1}$ at different sizes produced nanostructures of $\mathrm{MgO}$. Size and morphology of the $\mathrm{MgO}$ nanostructures depend on the initial particles size of compound $\mathbf{1}$.

\section{Acknowledgments}

The authors thank Tarbiat Modares University for the support and guidance. This work is funded by the Grant 2011-0014246 of the National Research Foundation of Korea.

\section{References}

[1] H. Li, M. Eddaoudi, M. O’Keeffe, and O. M. Yaghi, “Design and synthesis of an exceptionally stable and highly porous metalorganic framework," Nature, vol. 402, pp. 276-279, 1999.

[2] B. L. Chen, M. Eddaoudi, S. T. Hyde, M. O'Keeffe, and O. M. Yaghi, "Interwoven metal-organic framework on a periodic minimal surface with extra-large pores," Science, vol. 291, no. 5506, pp. 1021-1023, 2001.

[3] T. K. Maji, R. Matsuda, and S. Kitagawa, "A flexible interpenetrating coordination framework with a bimodal porous functionality," Nature Materials, vol. 6, pp. 142-148, 2007.

[4] T. K. Maji, K. Uemura, H. C. Chang, R. Matsuda, and S. Kitagawa, "Expanding and shrinking porous modulation based on pillared-layer coordination polymers showing selective guest adsorption," Angewandte Chemie, vol. 43, no. 25, pp. 3269-3272, 2004.

[5] S. Kitagawa, R. Kitaura, and S. Noro, "Functional porous coordination polymers," Angewandte Chemie, vol. 43, no. 18, pp. 2334-2375, 2004.

[6] S. Surblé, F. Millange, C. Serre et al., "Synthesis of MIL-102, a chromium carboxylate metal-organic framework, with gas sorption analysis," The Journal of the American Chemical Society, vol. 128, no. 46, pp. 14889-14896, 2006.

[7] T. Loiseau, C. Serre, C. Huguenard et al., "A rationale for the large breathing of the porous aluminum terephthalate (MIL-53) upon hydration," Chemistry, vol. 10, no. 6, pp. 1373-1382, 2004.

[8] C. Thompson, N. R. Champness, A. N. Khlobystov et al., "Using microscopic techniques to reveal the mechanism of 
anion exchange in crystalline co-ordination polymers," Journal of Microscopy, vol. 214, no. 3, pp. 261-271, 2004.

[9] G. J. Halder, C. J. Kepert, B. Moubaraki, K. S. Murray, and J. D. Cashion, "Guest-dependent spin crossover in a nanoporous molecular framework material," Science, vol. 298, no. 5599, pp. 1762-1765, 2002.

[10] K. L. Wong, G. L. Law, Y. Y. Yang, and W. T. Wong, "A highly porous luminescent terbium-organic framework for reversible anion sensing," Advanced Materials, vol. 18, no. 8, pp. 1051-1054, 2006.

[11] D. Maspoch, D. Ruiz-Molina, K. Wurst et al., "A nanoporous molecular magnet with reversible solvent-induced mechanical and magnetic properties," Nature Materials, vol. 2, no. 3, pp. 190-195, 2003.

[12] O. S. Wolfbeis, "The click reaction in the luminescent probing of metal ions, and its implications on biolabeling techniques," Angewandte Chemie, vol. 46, no. 17, pp. 2980-2982, 2007.

[13] S. Winter, E. Weber, L. Eriksson, and I. Csöregh, "New coordination polymer networks based on copper(II) hexafluoroacetylacetonate and pyridine containing building blocks: synthesis and structural study," New Journal of Chemistry, vol. 30, pp. 1808-1819, 2006.

[14] C. D. Wu, A. Hu, L. Zhang, and W. B. Lin, "A homochiral porous metal-organic framework for highly enantioselective heterogeneous asymmetric catalysis," The Journal of the American Chemical Society, vol. 127, no. 25, pp. 8940-8941, 2005.

[15] X. D. Guo, G. S. Zhu, Z. Y. Li, F. X. Sun, Z. H. Yang, and S. L. Qiu, "A lanthanide metal-organic framework with high thermal stability and available Lewis-acid metal sites," Chemical Communications, no. 30, pp. 3172-3174, 2006.

[16] U. Mueller, M. Schubert, F. Teich, H. Puetter, K. SchierleArndt, and J. Pastré, "Metal-organic frameworks-prospective industrial applications," Journal of Materials Chemistry, vol. 16, pp. 626-636, 2006.

[17] S. Hasegawa, S. Horike, R. Matsuda et al., "Three-dimensional porous coordination polymer functionalized with amide groups based on tridentate ligand: selective sorption and catalysis," The Journal of the American Chemical Society, vol. 129, no. 9, pp. 2607-2614, 2007.

[18] A. J. Fletcher, K. M. Thomas, and M. J. Rosseinsky, "Flexibility in metal-organic framework materials: impact on sorption properties," Journal of Solid State Chemistry, vol. 178, no. 8, pp. 2491-2510, 2005.

[19] J. A. R. Navarro, E. Barea, J. M. Salas et al., " $\mathrm{H}_{2}, \mathrm{~N}_{2}$, CO, and $\mathrm{CO}_{2}$ sorption properties of a series of robust sodalite-type microporous coordination polymers," Inorganic Chemistry, vol. 45, no. 6, pp. 2397-2399, 2006.

[20] M. Latroche, S. Surblé, C. Serre et al., "Hydrogen storage in the giant-pore metal-organic frameworks MIL-100 and MIL-101," Angewandte Chemie, vol. 45, no. 48, pp. 8227-8231, 2006.

[21] A. I. Skoulidas and D. S. Sholl, "Self-diffusion and transport diffusion of light gases in metal-organic framework materials assessed using molecular dynamics simulations," Journal of Physical Chemistry B, vol. 109, no. 33, pp. 15760-15768, 2005.

[22] D. N. Dybtsev, H. Chun, S. H. Yoon, D. Kim, and K. Kim, "Microporous manganese formate: a simple metal-organic porous material with high framework stability and highly selective gas sorption properties," The Journal of the American Chemical Society, vol. 126, no. 1, pp. 32-33, 2004.

[23] L. Pan, T. Frydel, M. B. Sander, X. Huang, and J. Li, "The effect of $\mathrm{pH}$ on the dimensionality of coordination polymers," Inorganic Chemistry, vol. 40, no. 6, pp. 1271-1283, 2001.
[24] J.-Z. Gu, W.-G. Lu, L. Jiang, H.-C. Zhou, and T.-B. Lu, “3D Porous metal-organic framework exhibiting selective adsorption of water over organic solvents," Inorganic Chemistry, vol. 46, no. 15, pp. 5835-5837, 2007.

[25] W. G. Lu, C. Y. Su, T. B. Lu, L. Jiang, and J. M. Chen, “Two stable 3D metal-organic frameworks constructed by nanoscale cages via sharing the single-layer walls," The Journal of the American Chemical Society, vol. 128, no. 1, pp. 34-35, 2006.

[26] Y. Liu, V. C. Kravtsov, R. Larsen, and M. Eddaoudi, "Molecular building blocks approach to the assembly of zeolite-like metalorganic frameworks (ZMOFs) with extra-large cavities," Chemical Communications, no. 14, pp. 1488-1490, 2006.

[27] Y. Q. Sun, J. Zhang, and G. Y. Yang, "A series of luminescent lanthanide-cadmium-organic frameworks with helical channels and tubes," Chemical Communications, no. 45, pp. 47004702, 2006.

[28] R. Q. Fang and X. M. Zhang, "Diversity of coordination architecture of metal 4,5-dicarboxyimidazole," Inorganic Chemistry, vol. 45, no. 12, pp. 4801-4810, 2006.

[29] L. Pan, X. Huang, J. Li, Y. Wu, and N. Zheng, "Novel singleand double-layer and three-dimensional structures of rareearth metal coordination polymers: the effect of lanthanide contraction and acidity control in crystal structure formation," Angewandte Chemie, vol. 39, no. 3, pp. 527-530, 2000.

[30] T. K. Maji, G. Mostafa, H.-C. Chang, and S. Kitagawa, "Porous lanthanide-organic framework with zeolite-like topology," Chemical Communications, no. 19, pp. 2436-2438, 2005.

[31] Z. Chen, Z. Fei, D. Zhao, Y. Feng, and K. Yu, "Synthesis, characterization and X-ray crystal structures of lithium coordination polymer from cyclobutane-1,1-dicarboxylic acid," Inorganic Chemistry Communications, vol. 10, pp. 77-79, 2007.

[32] X. Liu, G. Cong, B. Liu, W. T. Chen, and J. S. Huang, "A novel 2-D honeycomb-like lithium coordination polymer containing 42-membered rings," Crystal Growth \& Design, vol. 5, no. 3, pp. 841-843, 2005.

[33] X. Liu, G. C. Guo, A. Q. Wu, and J. S. Huang, "A novel stair-like lithium coordination polymer constructed from 4,4'bipyridine," Inorganic Chemistry Communications, vol. 7, no. 12, pp. 1261-1263, 2004.

[34] S. Horike, R. Matsuda, D. Tanaka, M. Mizuno, K. Endo, and S. Kitagawa, "Immobilization of sodium ions on the pore surface of a porous coordination polymer," The Journal of the American Chemical Society, vol. 128, no. 13, pp. 4222-4223, 2006.

[35] S. S. Han and W. A. Goddard, "Lithium-doped metal-organic frameworks for reversible $\mathrm{H}_{2}$ storage at ambient temperature," The Journal of the American Chemical Society, vol. 129, no. 27, pp. 8422-8423, 2007.

[36] K. L. Mulfort and J. T. Hupp, "Chemical reduction of metalorganic framework materials as a method to enhance gas uptake and binding," The Journal of the American Chemical Society, vol. 129, no. 31, pp. 9604-9605, 2007.

[37] F. Millange, G. Férey, M. Morcrette et al., "Mixed-valence li/febased metal-organic frameworks with both reversible redox and sorption properties," Angewandte Chemie, vol. 46, pp. 32593263, 2007.

[38] R. P. Davies, R. J. Less, P. D. Lickiss, and A. J. P. White, "Framework materials assembled from magnesium carboxylate building units," Dalton Transactions, no. 24, pp. 2528-2535, 2007.

[39] I. Senkovska and S. Kaskel, "Solvent-induced pore-size adjustment in the metal-organic framework $\left[\mathrm{Mg}_{3}(\mathrm{ndc})_{3}(\mathrm{dmf})_{4}\right]$ 
(ndc = naphthalenedicarboxylate)," The European Journal of Inorganic Chemistry, vol. 2006, no. 22, pp. 4564-4569, 2006.

[40] J. A. Rood, B. C. Noll, and K. W. Henderson, "Synthesis, structural characterization, gas sorption and guest-exchange studies of the lightweight, porous metal-organic framework $\alpha$ $\left[\mathrm{Mg}_{3}\left(\mathrm{O}_{2} \mathrm{CH}\right)_{6}\right]$," Inorganic Chemistry, vol. 45 , no. 14, pp. 5521$5528,2006$.

[41] C. A. Williams, A. J. Blake, C. Wilson, P. Hubberstey, and M. Schröder, "Novel metal-organic frameworks derived from group II metal cations and aryldicarboxylate anionic ligands," Crystal Growth \& Design, vol. 8, no. 3, pp. 911-922, 2008.

[42] J. Zhang, S. Chen, H. Valle et al., "Manganese and magnesium homochiral materials: decoration of honeycomb channels with homochiral chains," The Journal of the American Chemical Society, vol. 129, no. 46, pp. 14168-14169, 2007.

[43] J. A. Rood, W. C. Boggess, B. C. Noll, and K. W. Henderson, "Assembly of a homochiral, body-centered cubic network composed of vertex-shared $\mathrm{Mg}_{12}$ cages: use of electrospray ionization mass spectrometry to monitor metal carboxylate nucleation," The Journal of the American Chemical Society, vol. 129, no. 44, pp. 13675-13682, 2007.

[44] L. G. Qiu, A. J. Xie, and L. D. Zhang, "A zone-casting technique for device fabrication of field-effect transistors based on discotic hexa-peri-hexabenzocoronene," Advanced Materials, vol. 17, no. 6, pp. 684-689, 2005.

[45] S. S. Y. Chui, S. M. F. Lo, J. P. H. Charmant, A. G. Orpen, and I. D. Williams, "A chemically functionalizable nanoporous material $\left[\mathrm{Cu}_{3}(\mathrm{TMA})_{2}\left(\mathrm{H}_{2} \mathrm{O}\right)_{3}\right]_{\mathrm{n}}$," Science, vol. 283, no. 5405, pp. 1148$1150,1999$.

[46] O. M. Yaghi, H. Li, and T. L. Groy, "Construction of porous solids from hydrogen-bonded metal complexes of 1,3,5benzenetricarboxylic acid," The Journal of the American Chemical Society, vol. 118, no. 38, pp. 9096-9101, 1996.

[47] Z. Ni and R. I. Masel, "Rapid production of metal-organic frameworks via microwave-assisted solvothermal synthesis," The Journal of the American Chemical Society, vol. 128, no. 38, pp. 12394-12395, 2006.

[48] P. Amo-Ochoa, G. Givaja, P. J. S. Miguel, O. Castillo, and F. Zamora, "Microwave assisted hydrothermal synthesis of a novel $\mathrm{Cu}^{\mathrm{I}}$-sulfate-pyrazine MOF," Inorganic Chemistry Communications, vol. 10, no. 8, pp. 921-924, 2007.

[49] H. Fillion and J. L. Luche, Synthetic Organic Sonochemistry, Plenum Press, New York, NY, USA, 1998.

[50] L. G. Qiu, Z. Q. Li, Y. Wu, W. Wang, T. Xu, and X. Jiang, "Facile synthesis of nanocrystals of a microporous metalorganic framework by an ultrasonic method and selective sensing of organoamines," Chemical Communications, no. 31, pp. 3642-3644, 2008.

[51] G. W. Wagner, P. W. Bartram, O. Koper, and K. J. Klabunde, "Reactions of VX, GD, and HD with nanosize MgO," The Journal of Physical Chemistry B, vol. 103, no. 16, pp. 3225-3228, 1999.

[52] R. Z. Ma and Y. Bando, "Uniform MgO nanobelts formed from in situ $\mathrm{Mg}_{3} \mathrm{~N}_{2}$ precursor," Chemical Physics Letters, vol. 370, no. 5-6, pp. 770-773, 2003.

[53] Y. S. Yuan, M. S. Wong, and S. S. Wang, "Solid-state processing and phase development of bulk $(\mathrm{MgO})_{\mathrm{w}} / \mathrm{BPSCCO}$ hightemperature superconducting composite," Journal of Materials Research, vol. 11, no. 1, pp. 8-17, 1996.

[54] "Mercury 1.4.1," Cambridge Crystallographic Data Centre, Cambridge, UK, 2001-2005.
[55] R. Q. Fang and X. M. Zhang, "Diversity of coordination architecture of metal 4,5-dicarboxyimidazole," Inorganic Chemistry, vol. 45, no. 12, pp. 4801-4810, 2006. 

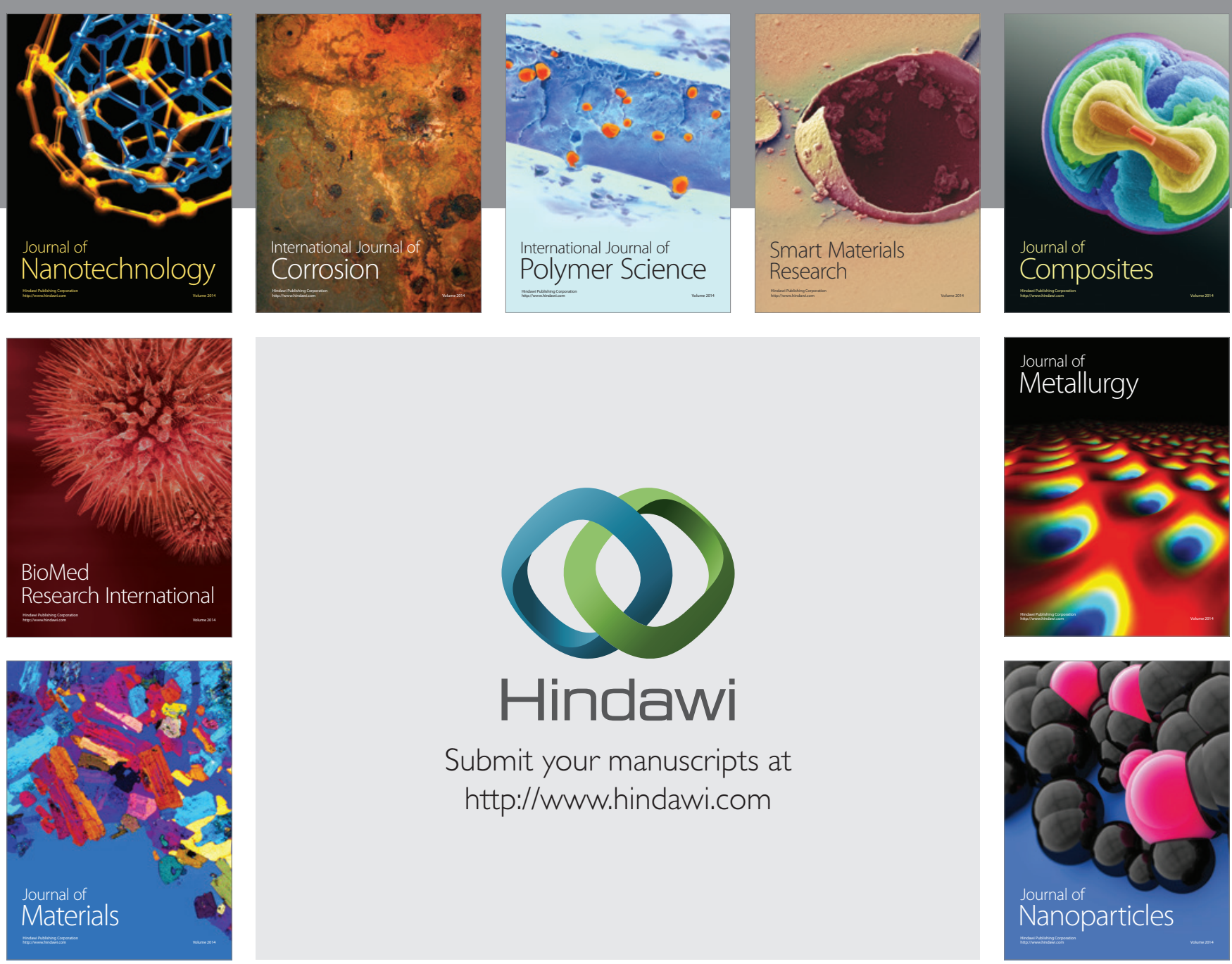

Submit your manuscripts at http://www.hindawi.com
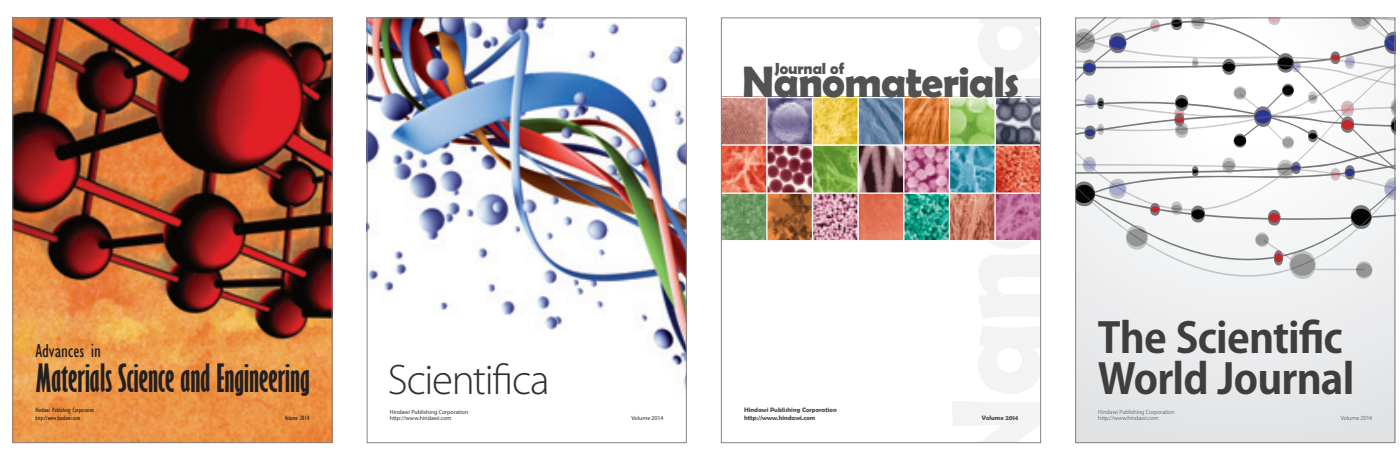

\section{The Scientific World Journal}
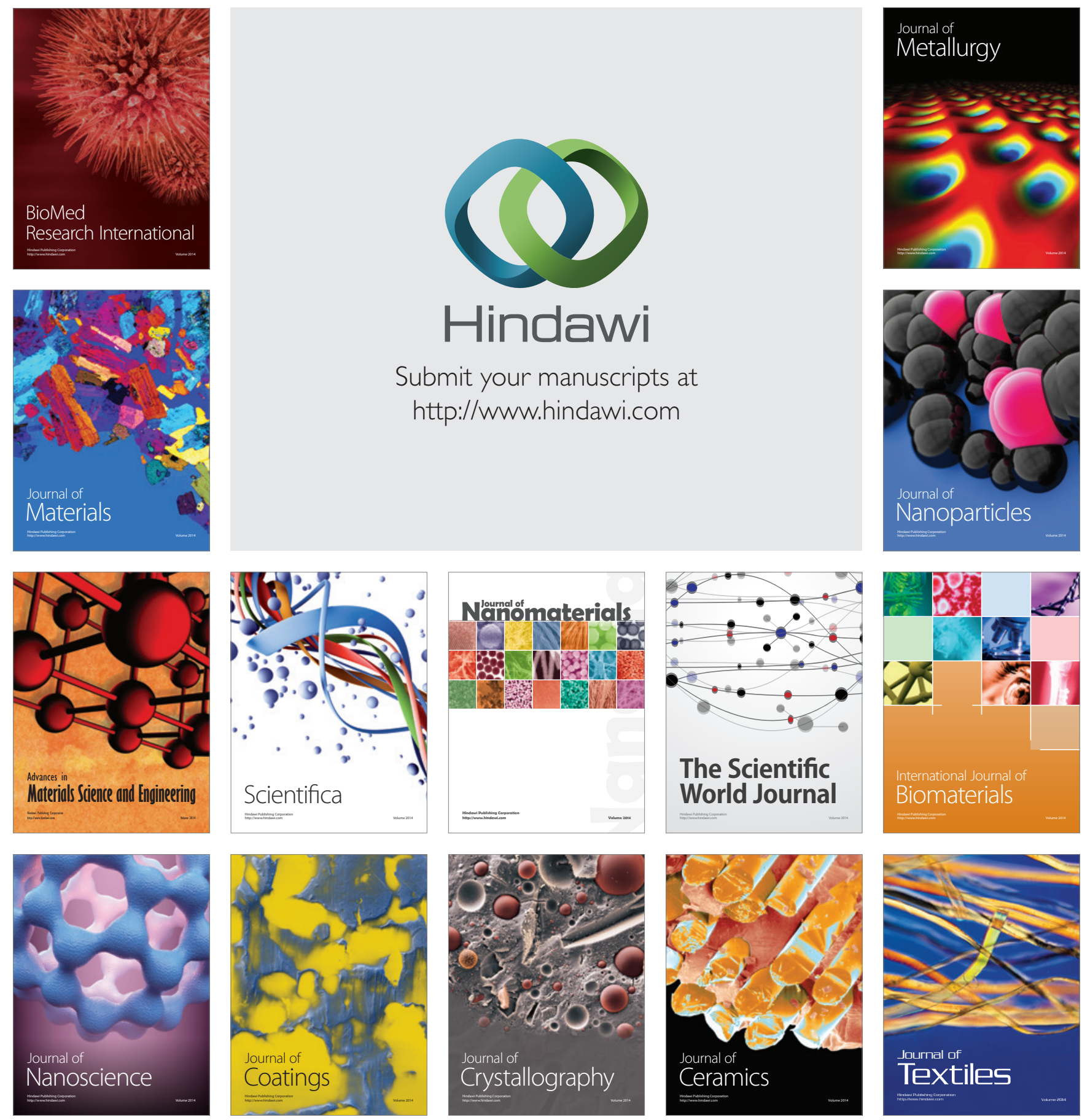